\title{
AVALIAÇÃO DA QUALIDADE DE LABNEH (IOGURTE GREGO): ESTUDO COM CONSUMIDORES
}

\author{
Quality evaluation of labneh: a study with consumers
}

\author{
Mariana Pereira Silveira ${ }^{{ }^{*}}$, Larissa de Oliveira Ferreira Rocha ${ }^{1}$, \\ Ana Luísa de Castro ${ }^{I}$, Danielly da Conceição Brandão ${ }^{l}$, \\ Tiago de Jesus Guedes ${ }^{I}$, Maraísa Kissila Oliveira Fernandes ${ }^{I}$
}

\begin{abstract}
RESUMO
O labneh (iogurte grego) é um tipo de leite fermentado caracterizado pelo processo de concentração de iogurtes tradicionais. Esse tipo de produto é relativamente novo no mercado alimentício e há poucos estudos de avaliação para seus parâmetros de qualidade. O objetivo deste trabalho foi avaliar a aceitação de três marcas comerciais de iogurte grego tradicional comercializados no município de Diamantina/MG e identificar os atributos que influenciam na qualidade do produto. Foram realizadas análises de cor ( $\left.\mathrm{L}^{*}, \mathrm{a}^{*}, \mathrm{~b}^{*}\right)$, textura, acidez titulável, pH e avaliação sensorial. Os resultados obtidos mostraram variação entre as amostras para todos os parâmetros analisados, exceto para o valor b*. Em relação à análise sensorial, por meio do teste de médias, observou-se que as marcas IA e IB foram as mais aceitas. Pelo mapa de preferência, pode-se inferir que a maior porcentagem de ácido lático da amostra IA e a firmeza de IB, foram os parâmetros responsáveis pela maior aceitação dessas marcas. Diante disso, observou-se que a textura e a acidez são atributos importantes na escolha do produto. Portanto, os resultados deste estudo podem auxiliar em trabalhos futuros de desenvolvimento de novas formulações, visando atender melhor às exigências do mercado consumidor.
\end{abstract}

Palavras-chave: leites fermentados; iogurte; análise sensorial.

\begin{abstract}
The labneh (Greek yoghurt) is a type of fermented milk product characterized by the concentration of the solids of the traditional yoghurt. The objectives of this

1 Universidade Federal dos Vales do Jequitinhonha e Mucuri (UFVJM), Rodovia MGT 367, Km 583, 5000, Alto da Jacuba, 39100-000, Diamantina, MG, Brasil. E-mail: mariana_silveira08@hotmail.com

* Autor para correspondência.
\end{abstract}

Recebido / Received: 27/07/2016

Aprovado / Approved: 14/02/2017 
study wereto evaluate the acceptance of 3 commercial brands of traditional Greek yogurt marketed in the city of Diamantina/MG; and to identify the attributes that influence the quality of the product. Analysis of the color $\left(\mathrm{L}^{*}, \mathrm{a}^{*}, \mathrm{~b}^{*}\right)$, texture, acidity, $\mathrm{pH}$ and sensory evaluation were performed. It was observed variation among the samples regarding all analyzed parameters but $b^{*}$ value. In relation to the sensory evaluation, throughout the test of means, it was observed that the brands IA and IB were the most accepted. Through the preference map analysis, it could be concluded that the higher percent of lactic acid of the sample IA and the higher firmness of the sample IB were the parameters responsible for the greater acceptance of these brands. It was observed that the texture and acidity are important attributes related to the choice of the product. Therefore, the results of this study may help in future work of development of new formulations.

Keywords: fermented milk; yogurt; sensory analysis.

\section{INTRODUÇÃO}

De acordo com a Instrução Normativa $n^{\circ} 46$ de outubro de 2007, entende-se por leites fermentados os produtos adicionados ou não de outras substâncias alimentícias, obtidas por coagulação e diminuição do $\mathrm{pH}$ do leite, ou reconstituído, adicionado ou não de outros produtos lácteos, por fermentação láctica mediante ação de cultivos de microrganismos específicos. Estes microrganismos devem ser viáveis, ativos e abundantes no produto final durante seu prazo de validade (BRASIL, 2007).

$\mathrm{O}$ iogurte, pertence à classe de leites fermentados e é definido como o produto cuja fermentação se realiza com cultivos proto-simbióticos de Streptococcus salivarius subsp. thermophilus e Lactobacillus delbrueckii subsp. bulgaricus, aos quais se podem acompanhar, de forma complementar, outras bactérias ácido-lácticas que, por sua atividade, contribuem para a determinação das características do produto final (BRASIL, 2007).

O iogurte concentrado pode considerarse como um produto intermediário entre os leites fermentados tradicionais e os queijos não maturados com alto teor de umidade como queijo quark, boursin e petit suisse. Varnan e Sutherland (1995) definem o tradicional pro- cesso do iogurte grego (iogurte concentrado), como o produto obtido a partir do iogurte tradicional, contudo diferenciado pelo processo de dessoragem, a nível industrial por centrifugação. Após este processo o iogurte torna-se espesso e cremoso, com uma concentração de sólidos totais de aproximadamente $24 \%$ e gorduras de $10 \%$.

$\mathrm{O}$ iogurte grego é um produto drenado e, portanto, concentrado em proteínas e gorduras, mais firme e viscoso que os demais produtos similares. No Brasil, como a regulação do iogurte grego ainda não foi definida, há marcas que adicionam outros ingredientes além de leite e fermento lácteo, como espessantes e creme de leite, com o objetivo de garantir a consistência característica do produto (COSTA et al., 2015).

Para o consumidor, um produto deve, além de ter ótimas características físicas, químicas e microbiológicas, oferecer características sensoriais que aprovem suas necessidades e anseios. Desta forma a qualidade do produto deve ser definida como a interação das características físicas e químicas com a aceitação dos consumidores (MINIM, 2006).

No setor de alimentos, a análise sensorial é de grande importância por avaliar a aceitabilidade mercadológica e a qualidade do produto, sendo parte inerente ao plano de 
controle de qualidade de uma indústria. É por meio dos órgãos dos sentidos que se procedem tais avaliações, e, como são executadas por pessoas, é importante um criterioso preparo das amostras testadas e adequada aplicação do teste para se evitar influência de fatores psicológicos (TEIXEIRA, 2009).

O objetivo deste trabalho foi avaliar por meio de análise sensorial a aceitação de iogurte grego tradicional de diferentes marcas. Além disso, determinar por meio de análises físicas e físico-químicas, características importantes para a qualidade desse tipo de produto, como cor, textura, $\mathrm{pH}$ e acidez total titulável, correlacionando os dados instrumentais com os dados sensoriais.

\section{MATERIAL E MÉTODOS}

\section{Material}

Foram realizadas análises em triplicata de três marcas de iogurte grego tradicional, adquiridos no comércio local da cidade de Diamantina, Minas Gerais. As marcas estudadas foram designadas de IA, IB e IC, objetivando manter a idoneidade de seus fabricantes. A descrição de cada produto, de acordo com o seu rótulo, pode ser observada na Tabela 1. O período de validade foi padronizado, adquirindo-se produtos com cerca de 10 dias após a fabricação, para que não houvesse diferenças bruscas na comparação das amostras.

Tabela 1 - Descrição dos ingredientes e informação nutricional dos iogurtes

\begin{tabular}{|c|c|c|}
\hline Amostra & Ingredientes & Informação nutricional (100g) \\
\hline IA & $\begin{array}{l}\text { Leite integral e/ou reconstituído, açúcar, leite } \\
\text { em pó desnatado, preparado de mel (água, } \\
\text { frutose, mel, amido modificado, aromatizantes, } \\
\text { acidulante ácido cítrico, conservador sorbato } \\
\text { de potássio e espessantes goma xantana e goma } \\
\text { guar), frutose, amido modificado, fermento } \\
\text { lácteo e estabilizante gelatina. }\end{array}$ & $\begin{array}{l}\text { Valor energético: } 121 \mathrm{Kcal} \\
\text { Carboidratos: } 16 \mathrm{~g}(5 \%) \\
\text { Proteínas: } 4,6 \mathrm{~g}(6 \%) \\
\text { Gorduras totais: } 4,1 \mathrm{~g}(7 \%) \\
\text { Gorduras saturadas: } 2,7 \mathrm{~g}(12 \%) \\
\text { Sódio: } 73 \mathrm{mg}(3 \%) \\
\text { Cálcio: } 151 \mathrm{mg}(15 \%)\end{array}$ \\
\hline IB & $\begin{array}{l}\text { Leite integral, açúcar, creme de leite, preparado } \\
\text { sabor creme (água, açúcar, aromatizante, sorbato } \\
\text { de potássio, ácido cítrico e goma xantana), } \\
\text { proteínas lácteas, leite em pó desnatado, ami- } \\
\text { do modificado, fermento lácteo e estabilizante } \\
\text { gelatina. }\end{array}$ & $\begin{array}{l}\text { Valor energético:126 kcal } \\
\text { Carboidratos: } 16 \mathrm{~g}(5 \%) \\
\text { Proteínas: } 4,8 \mathrm{~g}(6 \%) \\
\text { Gorduras totais:4,8 g }(9 \%) \\
\text { Gorduras saturadas: } 3,0 \mathrm{~g}(14 \%) \\
\text { Sódio: } 65 \mathrm{mg}(3 \%) \\
\text { Cálcio: } 142 \mathrm{mg}(14 \%)\end{array}$ \\
\hline $\mathrm{IC}$ & $\begin{array}{l}\text { Leite reconstituído e/ou pasteurizado inte- } \\
\text { gral, xarope de açúcar, preparado de fruta } \\
\text { (água, xarope de açúcar, açúcar, suco de maçã } \\
\text { concentrado, acidulante ácido cítrico, conser- } \\
\text { vador sorbato de potássio e espessante goma } \\
\text { xantana) e fermento lácteo. }\end{array}$ & $\begin{array}{l}\text { Valor energético: } 134 \mathrm{kcal} \\
\text { Carboidratos: } 17 \mathrm{~g}(6 \%) \\
\text { Proteínas: } 5,6 \mathrm{~g}(7 \%) \\
\text { Gorduras totais:5,0g }(9 \%) \\
\text { Gorduras saturadas: } 3,0 \mathrm{~g}(14 \%) \\
\text { Sódio: } 94 \mathrm{mg}(4 \%) \\
\text { Cálcio: } 177 \mathrm{mg}(18 \%)\end{array}$ \\
\hline
\end{tabular}




\section{Métodos}

As análises físico-químicas foram realizadas no Laboratório de Matérias-Primas, no Bloco de Laboratórios da Engenharia de Alimentos do Instituto de Ciência e Tecnologia (ICT) da Universidade Federal dos Vales do Jequitinhonha e Mucuri (UFVJM). As metodologias de análise foram realizadas conforme descrito abaixo.

\section{Avaliação de Cor}

A cor das amostras foi determinada em colorímetro Minolta, modelo CM5. Trabalhou-se com $\mathrm{D}_{65}$ (luz do dia), realizando a avaliação de padrões CieLab: L*, a* e b*.

\section{Acidez total titulável}

A acidez titulável foi determinada por titulometria com solução padrão de $\mathrm{NaOH}$ 0,1 M, (indicador: fenolftaleína a 1,0\%) e os resultados expressos em porcentagem de ácido lático (BRASIL, 2006).

\section{pH}

A determinação do $\mathrm{pH}$ foi feita por meio do método eletrométrico, utilizando-se um pHmetro digital (Instituto Adolfo Lutz IAL, 2008).

\section{Textura (TPA)}

A análise do perfil de textura, texture perfil analysis (TPA), foi realizada utilizando-se o texturômetro Stable Micro Systems, modelo TAX-XT Plus. Obtiveram-se os valores dos seguintes parâmetros, descritos por Szczesniak (1963): firmeza: força necessária para produzir uma deformação na amostra; coesividade: extensão a que um material pode ser deformado antes da ruptura; elasticidade: velocidade na qual um material deformado volta à condição não deformada, depois de removida a força; adesividade: energia necessária para superar as forças atrativas entre superfície do alimento e a de outros materiais com as quais o alimento está em contato e gomosidade: energia requerida para desintegrar um alimento até estar pronto para a deglutição.

As amostras foram avaliadas em triplicatas, no próprio pote dos iogurtes, que mantiveram mesmo padrão de altura $(10 \mathrm{~cm})$. Para os testes adotaram-se os mesmos parâmetros utilizados por Ramos et. al (2009): velocidade pré-teste: $2,0 \mathrm{~mm} / \mathrm{s}$; velocidade teste: $2,0 \mathrm{~mm} / \mathrm{s}$; velocidade pós teste: $2,0 \mathrm{~mm} / \mathrm{s}$; distância: $5 \mathrm{~mm}$; tempo de contato: $5 \mathrm{~s}$; força de contato: $100 \mathrm{~g}$; probe: cilindro metálico de $20,0 \mathrm{~mm}$.

\section{Análise de aceitação sensorial}

A análise foi realizada por 100 consumidores, de idades variando entre 18 e 36 anos, dentre eles estudantes, professores e funcionários da Universidade Federal dos Vales do Jequitinhonha e Mucuri. As amostras foram apresentadas de forma balanceada, segundo Wakeling; McFie (1995), oferecidas em copos descartáveis codificados com números de três dígitos. O teste foi realizado empregando-se cabines individuais e luz branca. Escalas hedônicas estruturadas de nove pontos, cujos extremos correspondem a desgostei extremamente (1) e gostei extremamente (9), foram utilizadas no teste de aceitação, conforme Stone; Sidel (1993), para cor, textura, sabor e impressão global. Utilizou-se também o teste com a escala do ideal, segundo Minim (2006), para avaliação do qual ideal encontravam-se os atributos acidez e firmeza. Utilizou-se a escala estruturada mista de sete pontos em que, $(+3)$ representava acidez/firmeza muito maior que o ideal; (0) ideal; (-3), acidez/firmeza muito menor que o ideal. 
O projeto de pesquisa foi aprovado pelo comitê de ética da Universidade Federal dos Vales do Jequitinhonha e Mucuri $\left(n^{\circ}\right.$ 55461616.6.0000.5108).

\section{Análise estatística}

Os resultados experimentais foram realizados com três repetições e submetidos à análise de variância (ANOVA), seguida de teste de médias (Tukey, $\mathrm{p}<0,05$ ), utilizando o software Statistica ${ }^{\circledR} 5.0$ (StatSoft, Poland).

Os resultados da avaliação sensorial e análises físico-químicas foram correlacionados por mapa de preferência externo de três vias, por meio de análise de fatores paralelos (PARAFAC). O mapa de preferência externo permite uma análise global dos resultados e sugere quais atributos ou descritores mais caracterizam as amostras. O mapa de preferência foi obtido no programa SensoMaker, versão 1.8 (NUNES et al., 2011).

Foram ainda, construídos histogramas de distribuição de frequência de notas, utilizando o programa Microsoft ${ }^{\circledR}$ Excel $^{\circledR} 2010$.

\section{RESULTADOS E DISCUSSÃO}

\section{Avaliação das características físico- químicas}

A Tabela 2 apresenta os valores obtidos experimentalmente nas análises físicoquímicas das amostras de iogurte grego.

Houve diferença significativa $(\mathrm{p}<0,05)$ entre as marcas de iogurtes analisadas para todos os parâmetros, exceto para o componente de cor $b^{*}$.

O parâmetro $b^{*}$ varia de amarelo $(+)$ a azul (-). Como todos os valores de $b^{*}$ foram positivos, isso significa que os iogurtes apresentaram maior reflexão associada à cor amarela $(+)$. As marcas IA e IB foram consideradas semelhantes, apresentando também tendência à cor amarela. A componente $\mathrm{a}^{*}$ varia de vermelho $(+)$ a verde (-). Todos os valores aferidos foram negativos, demonstrando que os iogurtes apresentaram leve tendência à cor verde (-). O valor $\mathrm{L}^{*}$ expressa a luminosidade ou claridade da amostra e varia de 100 (cem) para superfícies perfeitamente brancas até 0 (zero) para o preto. Devido à maior

Tabela 2 - Valores médios dos parâmetros avaliados ${ }^{1}$

\begin{tabular}{lcccc}
\hline \multicolumn{1}{c}{ Amostra } & IA & IB & IC & CV $(\%)$ \\
\hline L $^{*}$ & $92,90^{\mathrm{b}}$ & $92,70^{\mathrm{c}}$ & $93,22^{\mathrm{a}}$ & 0,00 \\
$\mathrm{a}^{*}$ & $-1,47^{\mathrm{a}}$ & $-0,83^{\mathrm{c}}$ & $-1,18^{\mathrm{b}}$ & 0,00 \\
$\mathrm{~b}^{*}$ & $12,14^{\mathrm{a}}$ & $12,18^{\mathrm{a}}$ & $11,89^{\mathrm{a}}$ & 0,00 \\
Acidez (g de ácido lático & $1,20^{\mathrm{a}}$ & $1,03^{\mathrm{c}}$ & $1,12^{\mathrm{b}}$ & 1,27 \\
em 100g de produto) & & & & \\
pH & $4,3^{\mathrm{a}}$ & $4,2^{\mathrm{b}}$ & $4,3 \mathrm{a}$ & 0,00 \\
Firmeza (g) & $164,61^{\mathrm{b}}$ & $205,36^{\mathrm{a}}$ & $165,88^{\mathrm{b}}$ & 2,13 \\
Adesividade (g.s) & $-122,76^{\mathrm{c}}$ & $-76,76^{\mathrm{b}}$ & $-31,04^{\mathrm{a}}$ & $-11,20$ \\
Elasticidade & $0,98^{\mathrm{b}}$ & $0,99^{\mathrm{b}}$ & $2,68^{\mathrm{a}}$ & 2,85 \\
Gomosidade & $107,42^{\mathrm{b}}$ & $121,97^{\mathrm{a}}$ & $123,40^{\mathrm{a}}$ & 58,11 \\
Coesividade & $0,66^{\mathrm{b}}$ & $0,59^{\mathrm{c}}$ & $0,74^{\mathrm{a}}$ & 2,52 \\
\hline
\end{tabular}

${ }^{1}$ Médias nas linhas seguidas por letras iguais não diferem entre si, a 5\% de significância, pelo teste de Tukey. $\mathrm{CV} \%=$ coeficiente de variação. 2 g: gramas; 3 g.s: gramas $\mathrm{x}$ segundos 
contribuição do parâmetro L* com a cor dos iogurtes, pode-se afirmar que os iogurtes apresentaram cor próxima ao branco. Em relação à luminosidade, a amostra IA apresentou-se mais clara que as demais.

$\mathrm{O}$ iogurte IA apresentou maior teor de ácido lático, seguido da amostra IC. O iogurte IB, por sua vez, foi aquele que apresentou menor porcentagem de ácido lático. Segundo Lima (2011) as mudanças na acidez do produto ocorrem, em maior ou menor grau, dependendo da temperatura de refrigeração, do tempo de armazenamento e do poder de pós-acidificação das culturas utilizadas e também se relacionam às mudanças nos valores de pH (LIMA, 2011). De acordo com Reis e colaboradores (2011), quanto maior a concentração de sólidos não gordurosos, maior o teor de caseína, que por sua vez possui caráter ácido aumentando assim a quantidade de $\mathrm{NaOH}$ a ser gasto na titulação e, consequentemente, provocando o aumento da acidez titulável. Observando a composição dos iogurtes analisados, verifica-se que a amostra IA mais ácida, apresenta maior teor de sólidos não gordurosos, convergindo com essa informação. Silva; Ueno (2013) encontraram valores de acidez titulável que variaram entre 0,93 e 1,32 g de ácido lático/100g de iogurte sabor natural, valores superiores aos encontrados por Longo et al. (2006) de 0,74 a 1,09 g de ácido lático/100 g de iogurte e próximos aos valores encontrados no estudo.

$\mathrm{O} \mathrm{pH}$ das amostras de iogurte variou de 4,2 a 4,3. Silva; Ueno (2013) avaliaram o pH de iogurtes de diferentes marcas de iogurte sabor natural e encontraram uma variação de $\mathrm{pH}$ de 4,0 a 4,2 entre $1 / 3$ e $2 / 3$ da vida útil, valores próximos ao encontrado no estudo.

$\mathrm{O}$ enriquecimento ou fortificação do leite implica no incremento da concentração de sólidos para obter as propriedades reológicas desejadas no iogurte. O objetivo principal é aumentar a porcentagem de proteína, a fim de potencializar a viscosidade do produ- to. A forma mais comum de concentração é adicinar leite em pó desnatado. Com o aumento da concentração proteica ocorre modificação da textura dos iogurtes, resultando em aumento da firmeza e intensificando a retenção de água pela matriz (MORR; HÁ, 1993). Também podem ser adicionados ao leite os espessantes e os estabilizantes permitidos pela legislação a fim de aumentar a viscosidade do produto final (ORDOÑEZ, 2005). Vários estudos têm indicado a importância de hidrocolóides na qualidade de iogurtes. As razões para usar hidrocolóides em produtos lácteos são duas: a ligação com a água e melhorias na textura. Os principais hidrocolóides utilizados para melhorar a textura e diminuir a sinérese são gomas xantana, guar e gelatina (GYAWALI; IBRAHIM, 2016). De acordo com Le et al. (2011), a gordura do leite age como estabilizante, aumentando a firmeza do iogurte e produz microestruturas mais densas quando comparado com iogurtes com baixa concentração de gordura.

Segundo Antunes et al. (2003), na produção de iogurte de consistência firme são indicados valores altos de firmeza, elasticidade e coesividade. Na pesquisa de Ramos et al. (2009), a presença de creme (com 67\% de gordura) na formulação de iogurte grego influenciou o perfil de textura das amostras principalmente nos parâmetros de adesividade, gomosidade e firmeza. Em relação à textura das amostras avaliadas, a amostra IB apresentou maior firmeza em relação às demais. Esse fato pode ser justificado pela combinação da adição de compostos que melhoram a textura, como leite em pó desnatado, estabilizante gelatina, amido modificado e proteínas lácteas na sua formulação, já que os teores de proteína e gorduras são semelhantes nas três amostras (Tabela 1). As demais amostras apresentaram menor firmeza e não houve diferença significativa entre elas. 


\section{Avaliação das características sensoriais}

As médias de aceitação para textura, sabor, cor e impressão global dos iogurtes encontram-se na Tabela 3 .

A análise de variância mostrou haver diferença significativa $(\mathrm{p} \leq 0,05)$ na aceitação das amostras em relação ao sabor e impressão global dos iogurtes.

As médias para impressão global, atributo de análise geral do produto, variaram de 7,05 a 7,69, o que corresponde na escala hedônica às categorias "gostei moderadamente" $\mathrm{e}$ "gostei muito", respectivamente.

Em relação aos atributos sabor e impressão global, a amostra IC diferiu significativamente $(\mathrm{p} \leq 0,05)$ das demais, sendo menos aceita, enquanto as amostras IA e IB foram as mais aceitas.
Para a análise dos dados obtidos da escala do ideal construíram-se histogramas de frequência.

Os histogramas de distribuição de frequência das notas do teste do ideal para a firmeza e acidez das amostras são apresentados nas Figuras 1 e 2, respectivamente.

Pode-se observar que a firmeza foi considerada ideal para todos os iogurtes analisados, já que apresentaram maiores frequências de respostas na nota ideal (nota $0)$. A amostra IB foi a que recebeu maior número de julgamentos $(67 \%)$ na categoria ideal, seguida da amostra IA $(58 \%)$ e IC (50\%) (Figura 1).

A maioria dos tratamentos recebeu maior frequência de respostas na categoria ideal (nota 0 ), indicando acidez próxima ao ideal. A amostra IA recebeu a maior porcentagem

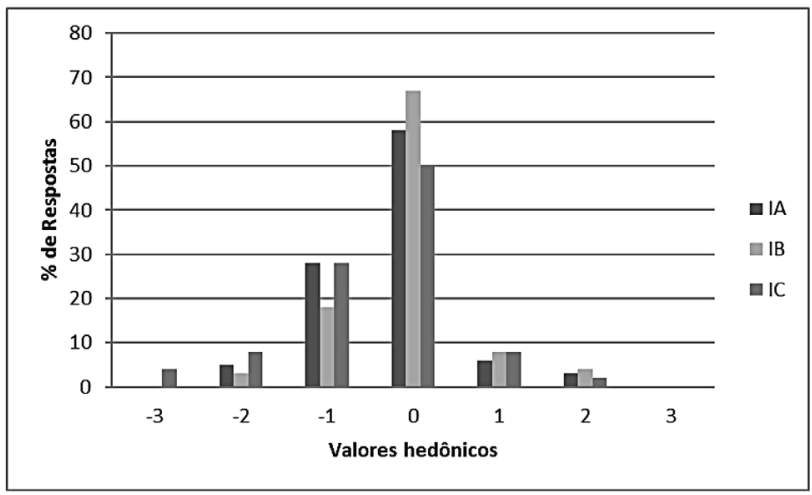

Figura 1 - Histograma de distribuição de notas atribuídas em relação à firmeza das amostras

Tabela 3 - Média das notas* na análise sensorial

\begin{tabular}{lcccc}
\hline Amostra & IA & IB & IC & CV (\%) \\
\hline Textura & $7,52^{\mathrm{a}}$ & $7,49^{\mathrm{a}}$ & $7,15^{\mathrm{a}}$ & 19,54 \\
Sabor & $7,34^{\mathrm{a}}$ & $7,63^{\mathrm{a}}$ & $6,62^{\mathrm{b}}$ & 21,34 \\
Cor & $7,43^{\mathrm{a}}$ & $7,46^{\mathrm{a}}$ & $7,29^{\mathrm{a}}$ & 19,79 \\
Impressão global & $7,53^{\mathrm{a}}$ & $7,69^{\mathrm{a}}$ & $7,05^{\mathrm{b}}$ & 17,22 \\
\hline
\end{tabular}

Médias nas linhas seguidas por letras iguais não diferem entre si, a 5\% de significância, pelo teste de Tukey; $\mathrm{CV} \%=$ coeficiente de variação; * (1-desgostei extremamente a 9-gostei extremamente) 
$(49 \%)$ de respostas na categoria ideal, seguida da amostra IB (47\%) e da amostra IC (40\%) (Figura 2).

Com o objetivo de compreender melhor a diferenciação das amostras analisadas, fez-se um estudo multivariado dos dados. O mapa de preferência externo, obtido através da análise de componentes principais foi escolhido por permitir uma discussão dos resultados quando explorados considerandose o peso de todas as medidas obtidas experimentalmente e sensorialmente. Na Figura 3 são mostrados os resultados gráficos que revelam a separação das amostras e as variáveis mais importantes nessa separação.

No mapa de preferência externo, os descritores são representados como triângulos, e as amostras localizam-se na mesma região dos triângulos (descritores) que as caracterizam. Portanto, através do gráfico (Figura 3), pode-se observar que a marca IB foi caracterizada por apresentar maior intensidade de firmeza e valor de a*, a marca IA foi caracterizada por apresentar maior porcentagem de ácido lático, enquanto que as amostra IC foi caracterizada por apresentar maiores valores de gomosidade, adesividade, elasticidade, coesividade e L*. Valores que corroboram com os resultados apresentados na Tabela 2. Não houve correlação entre pH e acidez para os iogurtes testados.
Observa-se pela tabela de teste de médias que nos atributos sabor e impressão global, as amostras IA e IB foram as preferidas. Correlacionando esses dados com os resultados do mapa de preferência externo (Figura 3), pode-se inferir que a maior porcentagem de ácido lático e a firmeza apresentada pela amostra IA e IB, respectivamente, foram parâmetros responsáveis pela aceitação dessas marcas, pois foram esses descritores que as caracterizaram. Esses resultados corroboram com os histogramas de frequência, os quais demonstram que a firmeza ideal foi apresentada pela amostra IB e a acidez ideal pela amostra IA. Portanto, observa-se que a textura e a porcentagem de ácido lático são parâmetros importantes na escolha do produto.

A preferência por iogurtes mais firmes foi descrita também por Lima e colaboradores (2011), que avaliaram características sensoriais de iogurte firme.

Medeiros et al. (2011) avaliou a aceitação de leites fermentados e observou maior preferência por leites fermentados mais ácidos, o que corrobora com os resultados obtidos.

Portanto, esses resultados mostram que a textura e a acidez são parâmetros importantes na escolha do produto.

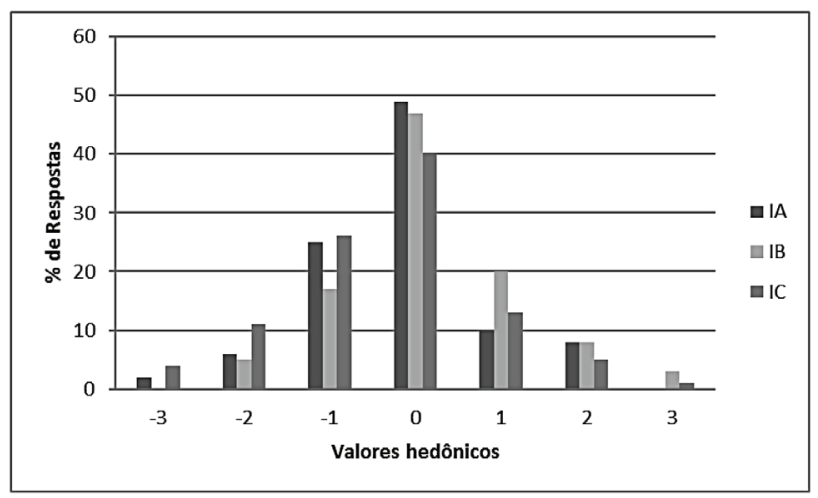

Figura 2 - Histograma de distribuição de notas recebidas em relação à acidez das amostras 


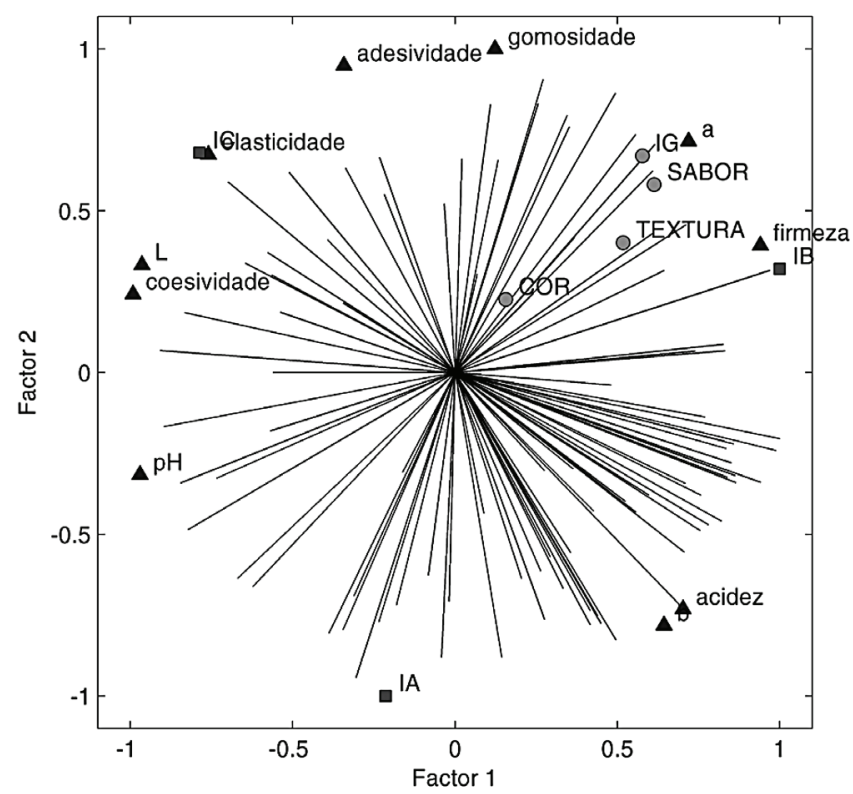

Figura 3 - Mapa de preferência externo para as amostras de iogurte grego

\section{CONCLUSÕES}

Os resultados obtidos mostraram variação na cor, textura e acidez entre as marcas de iogurte grego avaliadas. Pode-se observar que a textura e a acidez são parâmetros importantes na escolha do produto. Os resultados deste estudo podem auxiliar em trabalhos futuros de desenvolvimento de novas formulações visando atender melhor às exigências do mercado consumidor.

\section{REFERÊNCIAS}

Antunes, A. E. C.; MOTTA, E. M. P.; ANTUNES, A. J. Perfil de textura e capacidade de retenção de água de géis ácidos de concentrado protéico de soro de leite. Ciência e Tecnologia de Alimentos, v. 23, p. 183-189, 2003.

BRASIL. Ministério da Agricultura, Pecuária e Abastecimento. Instrução Normativa $\mathrm{n}^{\mathrm{o}} 46$, de 23 de outubro de 2007. Adota o Regulamento Técnico de Identidade e Qualidade de Leites Fermentados, anexo à presente Instrução Normativa. Diário Oficial da República Federativa do Brasil, 18 out. 2007.

BRASIL. Ministério da Agricultura, Pecuária e Abastecimento. Instrução Normativa $\mathrm{n}^{\circ}$ 68. Métodos analíticos oficiais físico-químicos, para controle de leite e produtos lácteos. Diário Oficial da República Federativa do Brasil, 12 dez. 2003. Disponível em: $<$ http://sistemasweb.agricultura.gov.br/>. Acesso em: 29 jun. 2016.

COSTA, M, F. et al. Desenvolvimento e caracterização de iogurte grego simbiótico sabor baunilha. Instituto Federal de Educação, Ciência e Tecnologia do Rio de Janeiro - IFRJ. Rio de Janeiro, 2015.

GYAWALI, R.; IBRAHIM, S. A. Effects of hydrocolloids and processing conditions on acid whey production with reference to 
Greek yogurt. Trends in Food Science \& Technology, v. 56, p. 61-76, 2016.

INSTITUTO ADOLFO LUTZ. Métodos físico-químicos para análise de alimentos. São Paulo: Instituto Adolfo Lutz, 2008. 1020 p.

LE, T. T. et al. Physical properties and microstructure of yoghurt enriched with milk fat globule membrane material. International Dairy Journal, v. 21, p. 798-805, 2011.

LIMA, C. M. F. Monitoramento de temperaturas de equipamentos de refrigeração em supermercados da cidade de Maceió - AL. Revista Higiene Alimentar, v. 25, n. 194195, p. 35-39, 2011.

LIMA, S. C. G. et al. Efeito da adição de diferentes sólidos na textura, sinérese e característica sensorial de iogurte firme. Revista do Instituto de Laticínios Cândido Tostes, v. 66, n. 383, p. 32-39, 2011.

MEDEIROS, E. J. L. et al. Leite fermentado de marcas comerciais: estudo da aceitação e correlação com pH e acidez. Revista do Instituto de Laticínios Candido Tostes, v. 66, n. 381, p. 46-51, 2011.

MINIM, V. P. R. Análise sensorial: estudos com consumidores. Viçosa: Editora. UFV, 2006, 225p.

MORR, C. V.; HÁ, Y. W. Whey protein concentrates and isolates: processing and functional properties. Food Science and Nutrition, v. 33, n. 6, p. 431-476, 1993.

NUNES, C. A.; PINHEIRO, A. C. M.; BASTOS, S. C. Evaluating consumer acceptance tests by three-way internal preference mapping obtained by parallel factor analysis (PARAFAC). Journal of Sensory Studies, Malden, v. 26, n. 2, p. 167-174, 2011.
ORDOÑEZ, J. A. P. et al. Tecnologia de alimentos: alimentos de origem animal. Porto Alegre: Artmed, 2005, 279p.

RAMOS, T. M. et al. Perfil de Textura de Labneh (Iogurte grego). Revista do Instituto de Laticínios Cândido Tostes, v. 64, n. 369, p. 8-12, 2009.

REIS, S. M.; PINTO, M. S.; BRANDI, I. V. Efeito do teor de sólidos não gordurosos e da concentração de sacarose na acidificação de iogurte por bactérias láticas. Revista do Instituto de Laticínios Cândido Tostes, v. 66, n. 378, p. 34-39, 2011.

SILVA, A. B. N.; UENO, M. Avaliação da viabilidade das bactérias lácticas e variação da acidez titulável em iogurtes com sabor. Revista do Instituto de Laticínios Cândido Tostes, v. 68, n. 390, p. 20-25, 2013.

STONE, H. S; SIDEL, J. L. Sensory evaluation practices. San Diego: Academic Press, 1993, $308 \mathrm{p}$.

SZCZESNIAK, A. S. Classification of textural characteristics. Journal of Food Science, Chicago, v. 28, n. 4, p. 385-389, 1963.

TEIXEIRA, L. V. Análise sensorial na indústria de alimentos. Revista do Instituto de Laticínios Cândido Tostes, v. 64, n. 366, p. 12-21, 2009.

VARNAN, A. H.; SUTHERLAND, J. P. Leche y produtos lácteos: tecnología, química y microbiologia. Zaragoza: Acribia, 1995. 476p.

WAKELING, I. N.; MAC FIE, H. J. H. Designing consumer trials balanced for first And higher orders of carry-over effect when only a subset of $\mathrm{k}$ samples from $\mathrm{t}$ may be tested. Food Quality and Preference, Barking, v. 6, n. 4, p. 299-308, 1995. 